\title{
Pre-Operative MRI in evaluation of Perianal fistulas
}

\author{
Milind Sawant ${ }^{1}$, Giriraj Singh ${ }^{2}$, Harish $\mathbf{S}^{3}$, Kaushik Roy ${ }^{4}$ \\ ${ }^{1}$ Assistant Professor, Department of Radiology, Command Hospital, Lucknow, Uttar Pradesh. India, ${ }^{2}$ Professor, \\ Department of Radiology, Command Hospital, Chandimandir, Panchkula. Haryana, India, ${ }^{3}$ Assistant Professor, \\ Department of Surgery, Command Hospital, Lucknow, Uttar Pradesh, India, ${ }^{4}$ Assistant Professor, Department of \\ Preventive and Social Medicine, Army College of Medical Sciences, New Delhi, India
}

Background: Perianal fistula is a common and often an extremely distressing disorder. MRI is a preferred modality for the preoperative assessment of perianal fistulas. Aims and Objective: To evaluate the accuracy and predictive values of pre-operative MRI in diagnosing severity of perianal fistulas and the conditions associated with it like internal anal opening, secondary tract, abscess and supralevator extension. Materials and Methods: In this study, 44 patients with clinically suspected perianal fistulas underwent MRI for the evaluation of severity and presence of the associated conditions. St James's University Hospital Classification was used to grade the perianal fistula. Pre-operative MRI grading was compared with the surgical findings in the 26 operated patients. Results: Out of 44 clinically suspected perianal fistulas, $41(93 \%)$ were diagnosed as perianal fistulas by MRI. The most common type was grade 1 seen in $12(27.3 \%)$ patients followed by grade 4 fistula seen in $10(22.7 \%)$ patients. All 26 patients evaluated by surgical findings for severity of perianal fistulas were found to be graded in identical grades by pre-operative MRI. MRI was $100 \%$ sensitive in picking up all five grades. Conclusion: MRI helps in the accurate delineation of fistulous tract, identification of secondary tract and abscess.

Key words: Perianal fistula; Preoperative MRI; Perianal fistula grading

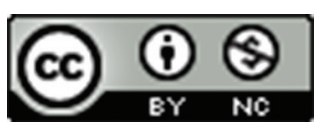

This work is licensed under a Creative Commons Attribution-NonCommercial 4.0 International License.

\section{INTRODUCTION}

Perianal fistula represents abnormal connection between the anal canal and one or more external openings in the perianal skin. It causes significant discomfort and annoyance to the patients affecting the quality of life. The incidence of perianal fistula ranges from approximately 1-2 per 10,000 individuals with an approximate 2:1 male to female predominance. The maximum incidence is between the third and fourth decades of life. ${ }^{1,2}$ Most of perianal fistulas are primary and are due to infection of anal glands located at the level of dentate line in mid anal canal - "the cryptoglandular hypothesis". ${ }^{3}$ These anal glands sometimes penetrate the internal sphincter to lie in the intersphicteric space. The infection of these anal glands sometimes results into abscess formation which bursts open in the intersphincteric plane downwards or outwards into the ischiorectal fossa through the external sphincter to form fistulous tract. Secondary causes of perianal fistulas include Crohn's disease, tuberculosis, trauma, pelvic infection, pelvic malignancy and radiotherapy. ${ }^{2}$ Though surgery is the definite treatment of perianal and anal fistulas, there is significant chance of recurrence. Successful surgical management of anal fistulas depends on the accurate preoperative identification of the course of the primary fistulous track and presence of any secondary extension or abscess. ${ }^{4}$ Failure to identify the secondary extension of the fistulous tract at the surgery results into the recurrence. Magnetic resonance imaging (MRI) owing to its superior soft tissue contrast resolution and multiplaner capabilities allows identification of fistulous tract, associated secondary tracts or abscesses if any. It 
also gives accurate information regarding the anatomic relation between the fistulous tract and sphincter complex, thus allowing the surgeon to choose optimal surgical approach to prevent disease recurrence and avoid potential complication like faecal incontinence. . $5,6^{5}$

The aim of the study was to evaluate the accuracy and predictive values of pre-operative MRI in the diagnosing severity of perianal fistulas and conditions associated with it like fistulous tract, internal anal opening, secondary tract, abscess and supra-elevator extension.

\section{MATERIALS AND METHODS}

In this study done in a tertiary care hospital of north India, we selected all patients with clinically diagnosed anal or perianal fistulas from Jan 2019 to Mar 2020. Fistulae associated with malignancy of the anorectum, Crohn's disease, tuberculosis or prior radiotherapy, all congenital fistulae and patients with contraindications for MRI (eg. Cochlear implants, cardiac pacemaker or severe claustrophobia) were excluded from the study. After obtaining written informed consent, the patients were evaluated by MR imaging.

MR imaging was performed using Magnetom Harmony 1.0 T unit system (Siemens Medical System; Erlangen, Germany) with a phase array coil. The patients were placed in supine position during image acquisition. The imaging volume was planned to incorporate the distal rectum and subcutaneous tissue with inclusion of anal canal, the sphincter muscles, the ischiorectal fossa, the levator muscle and the supralevator space. Imaging was performed with multiplanar T1-weighted, T2-weighted and T2 Fat Saturated and STIR (short tau inversion recovery) sequences. Fistula appeared as high signal intensity linear or curvilinear tract on T2 fat suppressed / STIR images and correspondingly is hypointense on $\mathrm{T} 1 \mathrm{~W}$ images relative to the sphincter complex in anal and perianal region. Contrast enhanced T1 fat suppressed sequences were performed when abscess was suspected on non-contrast images. The internal anal opening, course and location of the tract (intersphincteric or trans-sphincteric), any secondary tract/ramification or abscess cavity along the tract if any were noted. Fistula extending across the midline to the contralateral side was considered a horseshoe fistula. The location of the internal opening was identified on axial images using the "anal clock" where the anterior perineum is at 12 o'clock, the natal cleft at 6 o'clock, the left lateral aspect of the anal canal at 3 o'clock and the right lateral aspect at 9 o'clock. Location of external cutaneous opening of the fistula if present was noted in all the cases. The fistula was graded according to the St. James University Hospital classification system. ${ }^{2}$

\section{St James's University Hospital Classification}

Grade 1: Simple linear intersphincteric fistula

Grade 2: Intersphincteric fistula with an abscess or secondary track

Grade 3: Trans-sphincteric fistula

Grade 4: Trans-sphincteric fistula with an abscess or secondary track in the ischiorectal or ischioanal fossa

Grade 5: Supralevator and translevator disease

Surgery was carried out within 4 to 6 weeks of MRI in study patients requiring intervention. Pre-operative MRI grading was compared with the intra-operative surgical findings. Open Epi 7 was used for statistical analysis. Sensitivity, specificity, positive predictive value and negative predictive value of MRI in detecting internal opening, abscess, secondary tracks, supralevator extension was calculated. Cohen's Kappa coefficient was used to analyze the agreement between MRI and surgical findings based on severity of perianal fistulas and the conditions associated with it. The diagnostic standard of reference was the operative findings. Permission for study was taken from the Institutional Ethics Committee.

\section{RESULTS}

In our study population of 44 patients, 35(79.5\%) were males. The age ranged from 10 to 73 years with a mean of 38.9 years. All these patients presented with pain and/or discharge in the perianal region. Seven out of 44 patients had undergone previous fistula surgery without pre-operative MR imaging and had presented with recurrence. External opening could be visualised on MRI in 41(93.2\%) patients. Most common location of external opening in our study population was at 5 and 6 o'clock seen in $50 \%$ of the patients. Internal opening was visualised on MRI in 39(88.7\%) patients. The most common location of internal opening was at 6 o'clock seen in $18(40.9 \%)$ patients. The next common location was 7o'clock seen in 8(18.2\%) patients. Trans-sphincteric fistula (Figure 1) was found in $8(18.2 \%)$ patients. Secondary tract (Figures 2 and 3) was visualised in $14(31.8 \%)$ patients. 19 (43.2\%) patients had abscess/abscesses (Figure 4) along the tract, out of which four patients had horseshoe abscess. In $5(11.4 \%)$ patients, supralevator extension (Figures 5 and 6 ) were seen on MRI. Most common type of fistula was grade 1 (Figure 7) and seen in 12(27.3\%) patients (Table 1).

\begin{tabular}{lcc}
$\begin{array}{l}\text { Table 1: Grading of perianal fistula on MRI } \\
\text { according to St James's University Hospital } \\
\text { Classification }\end{array}$ & Frequency & Percentage \\
\hline Grades & 3 & 6.8 \\
\hline No fistula & 12 & 27.3 \\
Grade 1 & 6 & 13.6 \\
Grade 2 & 8 & 18.2 \\
Grade 3 & 10 & 22.7 \\
Grade 4 & 5 & 11.4 \\
Grade 5 & 44 & 100.0 \\
Total & & \\
\hline
\end{tabular}




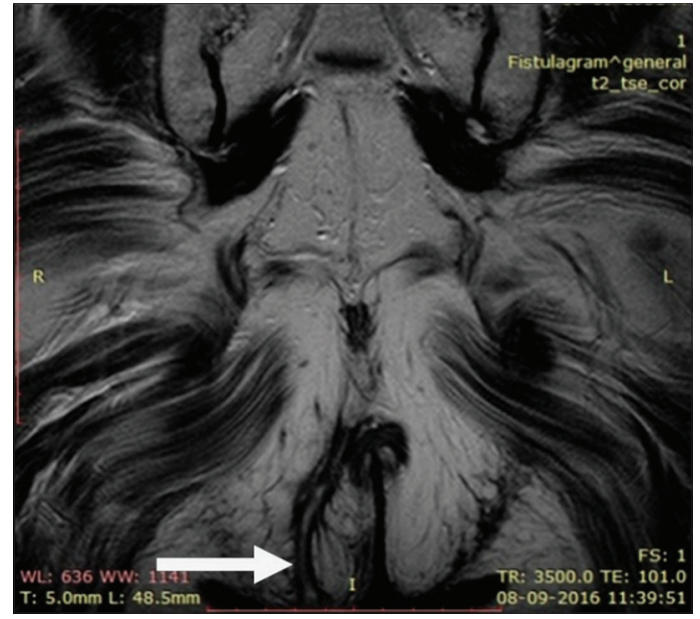

Figure 1: Grade 3: Trans-sphincteric fistula. T2W coronal image shows a linear non-branching hyperintense tract (white arrow) in the ischioanal fossa piercing the external sphincter.

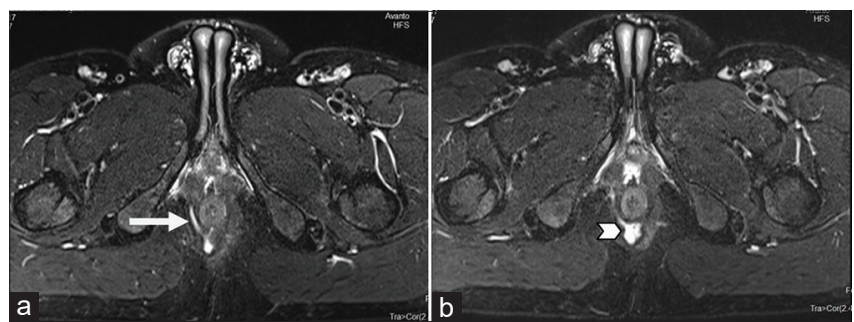

Figure 2: Grade 2: Intersphincteric fistula with an abscess or secondary track. (a) STIR axial image shows hyperintense tract with internal opening at 6 o'clock and ramification (white arrow) in the intersphincteric plane. (b) STIR axial image of the same patient in the next section also reveals small abscess $(\square)$ in the intersphincteric plane

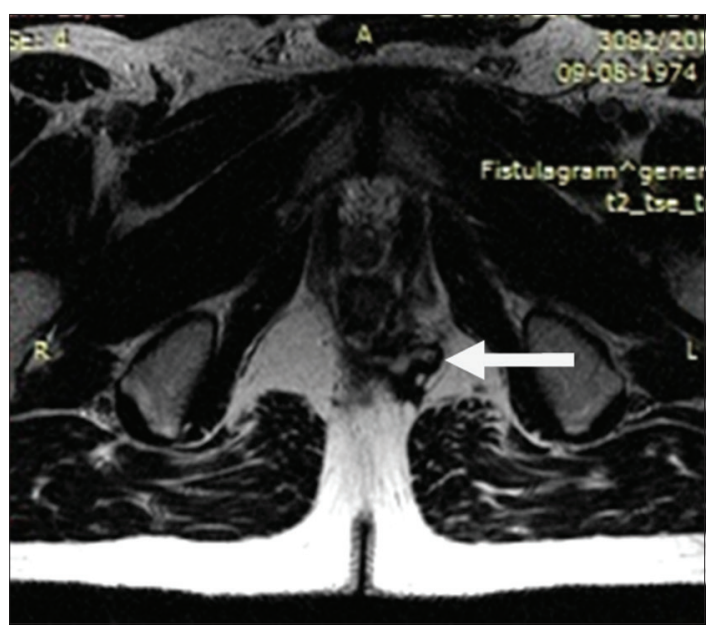

Figure 3: Grade 4: Transsphincteric fistula with secondary tract. T2 axial image shows a hyperintense tract with ramification (white arrow) extending into the left ischioanal fossa.

Out of 44 clinically suspected patients, 41patients were diagnosed with perianal fistulae on MRI. The remaining 3 patients who did not have fistula on MRI were not subjected to the surgery and they were managed conservatively. 26 $((63.4 \%)$ patients underwent surgery. The remaining

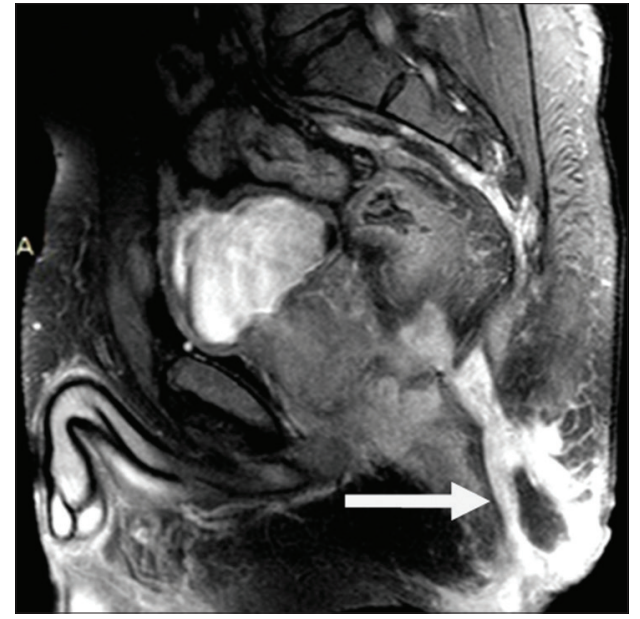

Figure 4: Perianal abscess. Same patient as in Figure 6. Post-contrast sagittal T1 fat saturated image shows abscess with thick enhancing walls (white arrow).

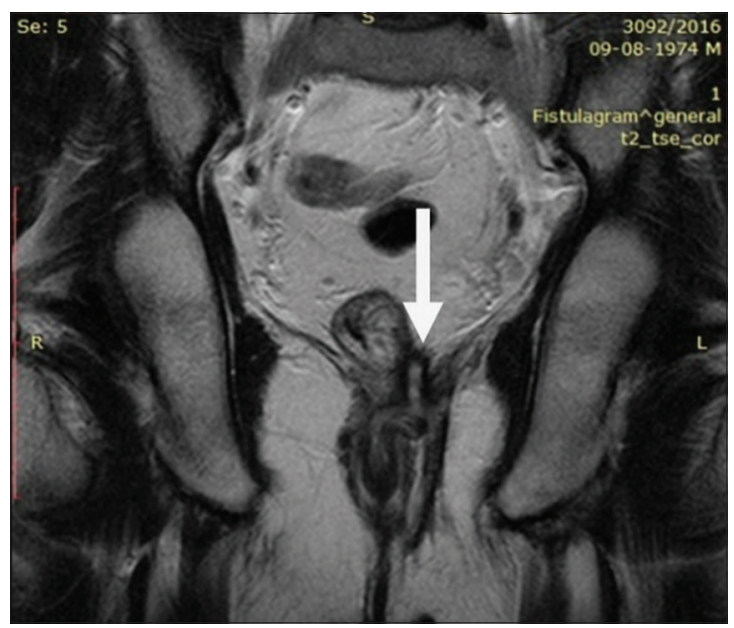

Figure 5: Grade 5: Supralevator and Translevator disease. T2 coronal image shows hyperintense fistula with supralevator extension (white arrow).

15 patients either refused surgery or were lost to follow up. For patients who underwent surgery, we compared the surgical findings with the preoperative MRI findings (Tables 2 and 3). MRI was 100\% sensitive in picking up related findings. Accuracy of diagnosis by MRI ranged from $80-100 \%$ for all conditions except secondary track $(78 \%)$. There was no instance where both surgery and preoperative MRI did not visualise the findings.

The classification of severity by grades were in absolute agreement between pre-operative MRI finding and surgical finding (Table 4).

\section{DISCUSSION}

In our study, 35 patients were males and the age ranged from 10 to 73 years with a mean of 38.9 years. This was in agreement with Halligan et al. who stated that the disease 
predominantly affects young adults and is more common in men. ${ }^{7}$ A total of seven out of 44 patients in our study had undergone previous fistula surgery and had presented with recurrence. Khera et al. in their retrospective study in 43 patients showed 8 patients who had recurrence after previous fistula surgery. ${ }^{8}$

In this study, the most common type was grade 1 fistula seen in $12(27.3 \%)$ patients followed by grade 4 fistula seen in $10(22.7 \%)$ patients. Rania $\mathrm{E}$ et al. iin a study of 24

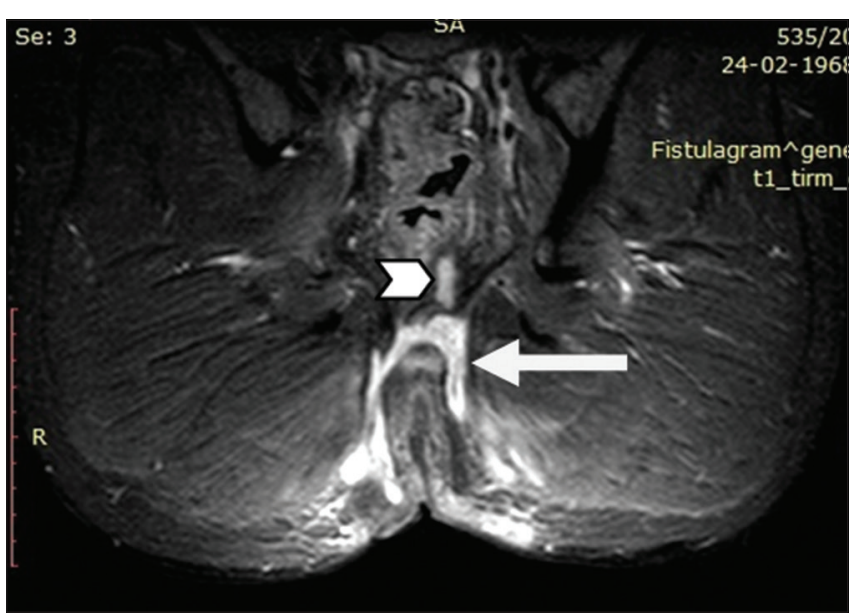

Figure 6: Grade 5: Supralevator and Translevator disease. STIR coronal image shows hyperintense horseshoe fistula (white arrow) with supralevator extension (๖).

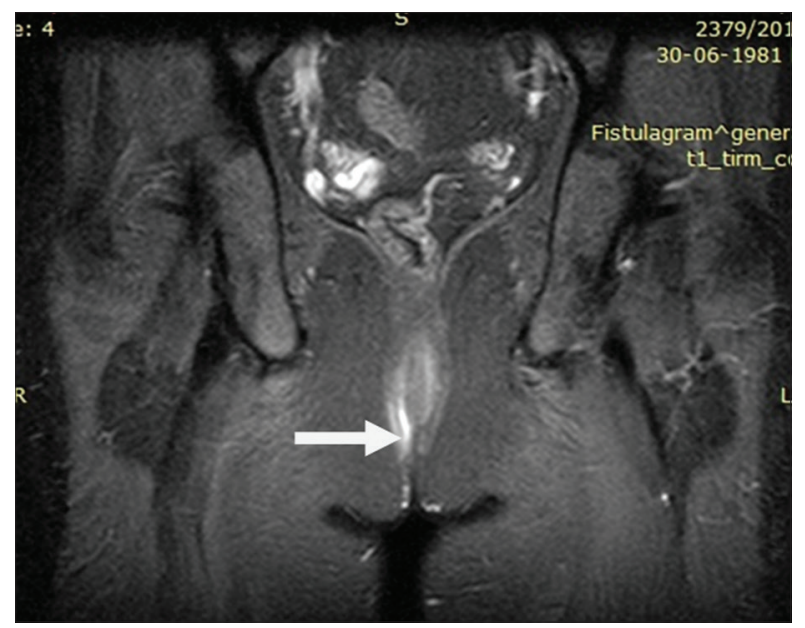

Figure 7: Grade 1: Simple linear intersphincteric fistula. STIR coronal image shows a linear hyperintense tract (white arrow) in the intersphincteric plane. patients have found $37.5 \%$ Grade 1 fistulas, $12.5 \%$ Grade 2 fistulas, $12.5 \%$ Grade 3 fistulas, $20.8 \%$ Grade 4 fistulas and $16.7 \%$ Grade 5 fistulas. ${ }^{9}$ In a prospective study by Naglaa D et al. in 25 patients with perianal sepsis, $3(12 \%)$ were Grade 1, 2(8\%) were Grade 2, 9(36\%) cases were Grade 3, 9(36\%) cases Grade 4 and 2(8\%) were Grade 5. ${ }^{10}$

External opening was not visualized in three patients with diagnosis of perianal abscess and sinus. This may be due to early stage of fistula formation, thus supporting cryptoglandular hypothesis. ${ }^{3}$ Most common location of external opening in our study population was 5 and 6 o'clock location seen in $50 \%$ of the patients.

In our study, internal opening was demonstrated in MRI in $39(88.7 \%)$ patients. The most common location of internal opening in our study was at 6 o'clock, seen in 18 (40.9\%) patients. The next common location was 7 o'clock seen in $8(18.2 \%)$ patients. Rania $\mathrm{E}$ et al. in their study found 6 o'clock location of internal opening as the most common and was seen in $50 \%$ of study group. ${ }^{9}$ We found that axial STIR or T2W fat suppressed images are ideal for identifying the fistulous tract and its internal opening into the anal canal.

Out of 26 patients who underwent surgery, MRI showed agreement with surgical findings with respect to internal opening in 23 patients (88.5\%). In the remaining 3 patients, internal opening was not found at surgery. Sometimes, the accurate location of the internal opening can be difficult to recognize at surgery due to local anatomical conditions as it is usually narrow, small or intermittently closed. The sensitivity, specificity, positive predictive value and negative predictive value of MRI in detecting the internal opening were $100 \%$, $50 \%, 87 \%$ and $100 \%$ respectively in our study. Pankaj Garg et al in their study of 229 patients found that MR imaging has sensitivity of $97.7 \%$ and specificity of $98.6 \%$ in detecting internal opening. ${ }^{11}$ Demonstration of level of the internal opening at MRI is important since this will determine the extent of sphincter division during fistulotomy.

In our study, simple non branching tracks were observed in $27(65.85 \%)$ patients, secondary tracks in $14(34.15 \%)$ patients, abscess in 19(46.45\%) patients (including horseshoe abscess in 4 patients) and supralevator extension in 5 patients $(12.2 \%)$. In the Rania E et al. study, simple non branching tracks were observed in $79.2 \%$ patients,

\begin{tabular}{|c|c|c|c|c|c|}
\hline Findings & Visualized on mri & Not visualized on mri & Visualized at surgery & Not visualized at surgery & Total \\
\hline Location of internal opening & 23 & 03 & 20 & 06 & 26 \\
\hline Simple Non-branching tract & 12 & 00 & 12 & 00 & 12 \\
\hline Secondary tract & 09 & 00 & 07 & 02 & 09 \\
\hline Abscess & 12 & 00 & 11 & 01 & 12 \\
\hline Supralevator extension & 5 & 00 & 5 & 00 & 5 \\
\hline
\end{tabular}




\begin{tabular}{|c|c|c|c|c|c|c|}
\hline Findings & Sensitivity & Specificity & PPV & NPV & $\begin{array}{l}\text { Observed } \\
\text { accuracy }\end{array}$ & Kappa coefficient \\
\hline Location of internal opening & $100 \%$ & $50 \%$ & $87.0 \%$ & $100 \%$ & $89 \%$ & 0.61 \\
\hline Simple non branching tracks & $100 \%$ & Cannot be calculated & $100 \%$ & Cannot be calculated & $100 \%$ & Cannot be calculated \\
\hline Secondary tracks & $100 \%$ & $0 \%$ & $77.9 \%$ & Cannot be calculated & $78 \%$ & Cannot be calculated \\
\hline Abscess & $100 \%$ & $0 \%$ & $91.7 \%$ & Cannot be calculated & $92 \%$ & Cannot be calculated \\
\hline Supralevator extension & $100 \%$ & Cannot be calculated & $100 \%$ & Cannot be calculated & $100 \%$ & Cannot be calculated \\
\hline
\end{tabular}

PPV: positive predictive value; NPV: negative predictive value

\begin{tabular}{lcc}
\multicolumn{3}{l}{$\begin{array}{l}\text { Table 4: Comparisons of perianal fistula grades } \\
\text { at MRI with those at surgery }\end{array}$} \\
\hline Grades & At Surgery & At MRI \\
\hline Grade 1 & $6(23 \%)$ & $6(23 \%)$ \\
Grade 2 & $5(19 \%)$ & $5(19 \%)$ \\
Grade 3 & $7(27 \%)$ & $7(27 \%)$ \\
Grade 4 & $6(23 \%)$ & $6(23 \%)$ \\
Grade 5 & $2(8 \%)$ & $2(8 \%)$ \\
Total & $26(100 \%)$ & $26(100 \%)$ \\
\hline
\end{tabular}

Observed Agreement: 100\%; Cohen's Kappa Coefficient= Cannot be calculated

secondary tracks in $20.8 \%$ patients, abscess in $20.8 \%$, and horseshoe abscess in $16.4 \%$ and supralevator extension in $20.8 \%$ patients. ${ }^{8}$ Supralevator extension of the disease is best seen on the coronal images.

All the 12 out of 26 patients who had simple tracks at MRI showed the same at surgery. Two patients who showed branching tracks at MRI were actually simple tracks at surgery. Retrospective review of MRI showed that the adjacent inflammation was misinterpreted as secondary tracks. The sensitivity of MRI in detecting simple tracks was $100 \%$ in our study. Beets - Tan RG et al in their study found that MR imaging is $100 \%$ sensitive, $86 \%$ specific with $88 \%$ positive predictive value and $100 \%$ negative predictive value in detecting simple tracks. ${ }^{12}$

Two out of 9 patients in whom MRI showed secondary tracks did not agree with surgical findings. Sensitivity and specificity of MRI in detecting secondary tracks is $100 \%$ and $89.74 \%$ respectively with $77.78 \%$ positive predictive value and $100 \%$ negative predictive value.

In 11 out of 12 patients in whom MRI showed abscess, the findings correlated with surgical findings. One patient in whom MRI showed abscess did not have abscess at surgery. This may be due to spontaneous discharge of abscess content before surgery. Hence sensitivity and specificity of MRI in detecting abscess is 100\% with $100 \%$ positive predictive value and 92\% accuracy. Kulvinder Singh et al in their study of 50 patients found to have a sensitivity of $87.50 \%$, specificity of $95.24 \%$, positive predictive value of $77.78 \%$ and negative predictive value of $97.56 \%$ in diagnosing abscess. ${ }^{13}$
Our study showed MRI has 100\% sensitivity with respect to supralevator extension. Beets-Tan RG et al also found similar result in their study in detecting supralevator extension. $^{12}$

Most of the comparative studies between MRI and other imaging studies like endo anal sonography agreed that MRI is the most accurate preoperative technique for classification of fistula in ano as well as in the evaluation of the primary track and any secondary extension. ${ }^{14-17}$ Preoperative MRI reveals additional diagnostic information which ultimately leads to the improved outcomes for surgical treatment. ${ }^{12,18,19}$

Recently, addition of diffusion weighted sequence (DWI) to the routine MRI has shown to improve the sensitivity and accuracy for the fistula visualization. ${ }^{20}$

\section{CONCLUSION}

Our results revealed that MRI is a valuable tool in preoperative evaluation of the perianal fistulas. It provided high resolution images of the anatomy of the anorectal region with accurate depiction of the fistulous tracts with their associated secondary ramifications and abscesses. It provides accurate roadmap for surgeons and may reduce the risk of surgical complications and recurrence.

\section{ACKNOWLEDGEMENT}

The authors take this opportunity to thank Department of Radiology and Surgery for their whole hearted support for this study.

\section{REFERENCES}

1. Zanotti C, Matinez- Puente C, Pascual I, Pascual M, Herreros D, Garcia-Olma D. An assessment of the incidence of fistula- in ano in four countries of the European Union. International Journal of Colorectal Disease. 2007; 22:1459-1462. https://doi.org/10.1007/s00384-007-0334-7

2. Morris J, Spencer JA and Ambrose NS. MR imaging classification of perianal fistulas and its implications for patient management. Radiographics. 2000; 20:623-635. 
https://doi.org/10.1148/radiographics.20.3.g00mc15623

3. Parks AG. Pathogenesis and treatment of fistula in ano. BMJ. 1961; 1(5224): 463-469.

https://doi.org/10.1136/bmj.1.5224.463

4. Seow-Choen and Philips RK. Insights gained from the management of problematical anal fistulae at St. Mark's Hospital, 1984-88. Br J Surg. 1991; 78(5): 539-541

https://doi.org/10.1002/bjs.1800780508

5. Beckingham IJ, Spencer JA, Ward J, Dyke GW, Adams C Ambrose NS, et al. prospective evaluation of dynamic contrast enhanced magnetic resonance imaging in the evaluation of fistula in ano. Br J Surg. 1996; 83 (10): 1396-1398. https://doi.org/10.1002/bjs.1800831022

6. Buchanan G, Halligan S, Williams A, Cohen CR, Tarroni D, Phillips RK, et al. Effect of MRI on clinical outcome of recurrent fistula in ano. Lancet. 1934; 224(5804): 1150-1156.

7. Halligan $\mathrm{S}$ and Stroker J. Imaging of fistula in ano. Radiology. 2006; 239(1): 18-33.

https://doi.org/10.1148/radiol.2391041043

8. Pushpinder S Khera, Hesham A Badawi and Ahmed H Afifi. MR in perianal fistula. Indian J Radiology imaging. 2010; 20(1): 53-57. https://doi.org/10.4103/0971-3026.59756

9. Rania EM and Dina M. Role of MRI in pre operatives' assessment of the ano-rectal fistula. The Egyptian journal of radiology and nuclear Medicine. 2014. L4-5: 35-47. https://doi.org/10.1016/j.ejrnm.2013.10.008

10. Naglaa D, Shafeya RE, Zakariaa Y and Elkhadrawy O. Magnetic resonance imaging evaluation of perianal fistula. Egypt $\mathrm{J}$ Radiol Nucl Med. 2013; 44(4); 705-711.

https://doi.org/10.1016/j.ejrnm.2013.09.003

11. Garg P, Singh $P$ and Kaur B. Magnetic Resonance Imaging (MRI): Operative Findings Correlation in 229 Fistula-in-Ano Patients. World Journal of Surgery. 2017; 41(6):1618-1624. https://doi.org/10.1007/s00268-017-3886-x

12. Beets-Tan RG, Beets $G L$, van der Hoop AG, Kessels AG, Vliegen RF, Baeten CG, et al. Preoperative MR imaging of anal fistulas: does it really help the surgeon? Radiology. 2001; 218(1): 75-84. https://doi.org/10.1148/radiology.218.1.r01dc0575

13. Singh K, Singh N, Thukral CL, Singh KP and Bhalla V. Magnetic Resonance Imaging (MRI) Evaluation of Perianal Fistulae with Surgical Correlation. Journal of Clinical and Diagnostic Research. 2014; 8(6): RC01-RC04 https://doi.org/10.7860/JCDR/2014/7328.4417

14. Soendersing $D$ and Shahid M. MRI of perianal fistulas. Semin Ultrasound CT MRI. 2005; 26: 247-258. https://doi.org/10.1053/j.sult.2005.04.004

15. Schwartz DA, Wiersema MJ, Dudiak KM, Fletcher JG, Clain JE, Tremaine WJ, et al. A comparative of endoscopic ultrasound, MRI and exam under anesthesia for evaluation of Crohn's perianal fistula. Gastroenterology. 2001; 121:1064-1072. https://doi.org/10.1053/gast.2001.28676

16. Buchanan GN, Halligan S, Bartram $\mathrm{Cl}$, Williams AB, Tarroni D and Cohen CRG. Clinical examination, endosonography and MR imaging in preoperative assessment of fistula in ano. Radiology. 2004; 233:674-681. https://doi.org/10.1148/radiol.2333031724

17. Dariusz W, Tomasz A, Jerz A, Kluczewska E and Kozinska-Marek E. Usefulness assessment of preoperative MRI Fistulography in patients with perianal fistulas. Radiology. 2011; 76(4): 40-44.

https://www.ncbi.nlm.nih.gov/pubmed/22802853 .

18. Buchanan GN, Halligan S, Bartram $\mathrm{Cl}$, Williams AB, Tarroni D and Cohen CRG. Clinical examination, endosonography, and MR imaging in preoperative assessment of fistula in ano: comparison with outcome-based reference standard. Radiology. 2004; 233(3):674-681.

https://doi.org/10.1148/radiol.2333031724

19. Buchanan G, Halligan S, Williams A, Cohen CRG, Tarroni D, Phillips RKS, et al. Effect of MRI on clinical outcome of recurrent fistula-in-ano. Lancet. 2002; 360(9346):1661-1662. https://doi.org/10.1016/S0140-6736(02)11605-9

20. Algazzar HY, Eldib DB, Bahram MA and Zaher NA. Preoperative MRI of perianal fistula evaluation and its impact on surgical outcome. Egypt J Radiol Nucl Med. 2019 50:71. https://doi.org/10.1186/s43055-019-0085-9

\footnotetext{
Author's Contribution:

MS- Concept and design of the study; prepared first draft of manuscript; GS- Interpreted the results; reviewed the literature and manuscript preparation;

HS- Concept, coordination, review of literature and manuscript preparation; KR- Statistically analysed and interpreted, preparation of manuscript and revision of the manuscript.

Work attributed to:

Command Hospital, Lucknow, Uttar Pradesh, India.

Orcid ID:

Dr. Milind Sawant- (1) https://orcid org/0000-0001-6424-4520

Dr. Giriraj Singh- (1) https://orcid.org/0000-0002-9380-9057

Dr. Harish S- (i) https://orcid.org/0000-0003-2331-6879

Dr. Kaushik Roy- (i) https://orcid.org/0000-0002-5245-9011

Source of funding: None, Conflict of Interest: None.
} 